\title{
Effect of Body Mass Index on Anesthesia Characteristics and Vasopressor Requirements during Spinal Anesthesia for Elective Cesarean Section
}

\author{
Mohamed Elmeliegy \\ Anaesthesia Department, Benha University, Benha, Egypt \\ Email: mohamedfouaaaaad2020@gmail.com
}

How to cite this paper: Elmeliegy, M. (2020) Effect of Body Mass Index on Anesthesia Characteristics and Vasopressor Requirements during Spinal Anesthesia for Elective Cesarean Section. Open Journal of Anesthesiology, 10, 157-169.

https://doi.org/10.4236/ojanes.2020.104014

Received: December 22, 2019

Accepted: April 27, 2020

Published: April 30, 2020

Copyright ( 2020 by author(s) and Scientific Research Publishing Inc. This work is licensed under the Creative Commons Attribution International License (CC BY 4.0).

http://creativecommons.org/licenses/by/4.0/

(c) (i) Open Access

\begin{abstract}
Background: There is a debate about the dose of hyperbaric bupivacine for spinal anesthesia for cesarean delivery in obese parturients. While it is concessive that the dose of spinal bupivacine is reduced in pregnant compared with non-pregnant parturient due to many factors. But it is still controversial whether local anesthetic should further reduce in obese patients or not. In this perspective, observation study, we tested the influence of BMI on vasopressor requirements and block height. Methods: Three groups of 40 parturients, group A (Body mass index (BMI) $<30 \mathrm{~kg} / \mathrm{m}^{2}$ ), group B (BMI $30-45$ $\left.\mathrm{Kg} / \mathrm{m}^{2}\right)$ and group $\mathrm{C}\left(\mathrm{BMI}>45 \mathrm{~kg} / \mathrm{m}^{2}\right)$ requiring elective cesarean section were recruited all patients received $12.5 \mathrm{mg}$ subarachnoid hyperbaric bupivacine combined with 20 ug fentanyl. Dermatomal levels were assessed after subarachnoid injection using touch sensation at 2 minutes interval for first 10 minutes then every 5 minutes. Vasopressor requirements in the first $45 \mathrm{mi}$ nutes after subarachnoid injection, and maximum block heights using touch sensation were assessed as primary outcomes. Secondary outcomes were extent of motor block (peak flow rate), technique difficulty (number of attempts), maternal side effects and neonatal outcomes. Results: There was no significant difference in mean blood pressure (MBP) between group A and B but the difference was significant in group $\mathrm{C}$ in relation to other two groups, mean number of hypotensive episodes was significantly higher in group $C$ than group A, B with no significant difference in incidence between group A and B $(\mathrm{P}<0.001)$ (3.28 vs 3.98 vs 5.98 ). Total dose of vasoprenor and total volume of fluid infused were higher in group $\mathrm{C}$ than group A, B. In group A the maximum block level extended above $\mathrm{T} 3$ in 5 patients (12.5\%), with predominance of T5 (35\%), in group B the maximum level extended above T3 in 10 patients
\end{abstract}


(25\%) with predominance of $\mathrm{T} 4(45 \%)$ and in group C the maximum block level extended above T3 in 21 patients (52.5\%) with predominance of T3 (32.5\%). Significant decrease in the mean of peak expiratory flow rate (PEFR) in group $\mathrm{C}$ than group A, B, 30 minutes after subarachnoid injection of bupivacine $(\mathrm{P}=0.004)(343.75 \pm 35.06$ vs $335.36 \pm 32.96$ vs $320.38 \pm 24.0 \mathrm{ml})$. No cases required analgesic supplementation. Conclusion: Sensory testing using touch modality to detect extent of anesthesia, showed at 25 minutes after spinal anesthesia induction, significantly higher level in group $C$ than the other two groups. Vasopressor requirements during the first 45 minutes of spinal anesthesia were not different between group A, B but significantly higher in group C. Time for regression of anesthesia was longer in group $\mathrm{C}$, which may be helpful regarding longer surgical time. Single shots spinal anesthesia of 12.5 mg hyperbaric bupivacine produce clinically equivalent effect in parturients with BMI $<45 \mathrm{Kg} / \mathrm{m}^{2}$ with no need for dose reduction but caution and dose adjustment recommended in parturients with $\mathrm{BMI}>45 \mathrm{Kg} / \mathrm{m}^{2}$.

\section{Keywords}

Cesarean Section, Obesity, Spinal Anesthesia

\section{Introduction}

Neuroaxial anesthesia using local anesthetics and opioids is the preferred anesthetic technique for cesarean delivery in both non-obese and morbidly obese parturients [1]. As BMI increases, challenges, procedural difficulty, maternal and fetal risk increase [2]. Maternal obesity has shown to increase failure rate of epidural top-up while spinal anesthesia following epidural top-up may lead to extensive high sensory block [3], besides limited resources in peripheral hospitals therefore spinal anesthesia is favoured technique in most cases of morbidly obese.

Many factors affect spread of local anesthetics and extent of block. Parturients' weight may be a significant variable in predicting extent of block and subsequently hypotention and the need for vasopressors in morbidly obese parturients some anesthesiologists adjust their doses aiming to obtain adequate surgical anesthesia with minimal haemodynamic changes. In adequate neuroaxial block with conversion to general anesthesia in morbidly obese patients in non ideal situations associated with catastrophic events.

2 recent studies suggest similarity between obese and non obese patients in median effective dose $\left(\mathrm{ED}_{95}\right)$ for spinal bupivacine [4] [5]. Our study compares response to same dose of intrathecal hyperbaric bupivacine $0.5 \% 12.5 \mathrm{mg}$ and fentanyl $20 \mathrm{ug}$, our usual practice in non obese and obese parturients aiming to observe changes in blood pressure and vasopressors dose used to maintain haemodynamics during first 45 minutes, maximum sensory block at 25 minutes, as measured by the sensation to touch. Secondarily, extent of motor block (peak flow rate), technique difficulty (number of attempts), time intervals related to the procedure, maternal side effects and neonatal outcome. 


\section{Patient and Methods}

This stratified cohort study was conducted at Benha University Hospital, following approval from research ethics committee, 120 non laboring parturients with gestational age $>37$ week, age 18 - 40 years, carrying singleton pregnancy and scheduled to have elective cesarean section under spinal anesthesia were included in our study and all patients gave informed written consent after detailed explanation of the procedure. Among them 40 women with BMI $<30 \mathrm{Kg} / \mathrm{m}^{2}$ (group A), another 40 women with BMI $30-45 \mathrm{Kg} / \mathrm{m}^{2}$ (group B) and the last 40 parturients with BMI $>45 \mathrm{Kg} / \mathrm{m}^{2}$ (group C). Parturients were weighted at the time of recruitment, because we did not have access to the parturients in early pregnancy. Parturients with preexisting hypertention, preeclampsia, multiple pregnancy, placenta previa, active labor, more than 2 previous cesarean deliveries and those who refused or have contraindications to spinal anesthesia were excluded from the study.

On arrival in operating theatre, intravenous access was secured with an $18 \mathrm{G}$ cannula; $4 \mathrm{mg}$ ondanosterone, $50 \mathrm{mg}$ rantidine were administrated and intravenous cefazolin 1 or 2 gm was infused depending on maternal weight below or above $80 \mathrm{Kg}$. Prehydration with $10 \mathrm{ml} / \mathrm{Kg}$ of normal saline was administrated over course of 15 - 20 minutes. Standard monitoring was applied using pulse oximeter, 3-lead electrocardiogram and non invasive blood pressure monitoring (using appropriate sized cuff, allowing enough space for insertion of one finger between cuff and skin). Baseline blood pressure recorded in left later position, was the average of 2 readings taken 2 minutes apart after arrival to operation theatre and before doing any procedure.

After aseptic measures, skin infiltration with $2 \%$ lidocaine, a $25 \mathrm{G}$ pencil point spinal needle inserted in the midline at L3-4 vertebral interspace (L3-4 level just marked by special investigator in all patients using ultrasound scan) with the patient in sitting position, after confirming a free flow of cerebrospinal fluid, subarachnoid injectate consisted of $2.5 \mathrm{~mL}$ (12.5 mg) hyperbaric bupivacine $0.5 \%$ and $20 \mu \mathrm{g}$ fentanyl were injected over 30 seconds; then patients immediately turned supine and wedge position maintained to minimize aortocaval compression. We did not supply oxygene unless $\mathrm{SPO}_{2}$ decrease to $92 \%$.

The levels of sensory block were evaluated bilaterally (by single investigator in all cases who was unaware about nature of the study), in midclavicular line by pin-prick sensation at 2-minute intervals for first 10 minutes then every $5 \mathrm{mi}$ nutes after subarachnoid injection. The following informations were collected: onset of sensory blockade to $\mathrm{T}_{6}$ level, maximum extent of sensory block and time until regression of sensory block below $\mathrm{L}_{1}$. Level of motor block assessed using modified Bromage scale $(0=$ no impairement; $1=$ unable to raise extended legs but able to move knee and ankles; 2 = unable to extend legs or flex knees but able to more feet; 3 = unable to flex ankles, Knees or hips) at 2 minute intervals. The degree of motor block, onset time and duration of block were recorded. 
A Peak flow meter (Digital mini-Wright, Alliance Tech Medical, Inc., USA) was used to assess the spinal anesthesia effect on respiratory function readings were taken in preparatory area of the operating room, with the patient in supine wedged position (baseline) and second reading 30 minutes after subarachnoid injection.

Heart rate, blood pressure were recorded at 1 minute interval for the first 20 minutes then every 5 minutes till end of surgery hypotention was defined as more than $20 \%$ decrease in MAP or SBP $<100 \mathrm{mmHg}$, and was treated with 5 $10 \mathrm{mg}$ intravenous ephedrine or $50-100 \mu \mathrm{g}$ phenylephrine boluses at discretion of the anesthesiologist. Bradycardia defined as heart rate $<50$ beat per minute and treated with intravenous atropine $0.6 \mathrm{mg}$. The total amounts of intravenous administrated fluid, total doses of vasopressors and number of hypotensive episodes were recorded as well.

Other complications also recorded as nausea, vomiting, pruritis, respiratory depression $\left(\mathrm{SPO}_{2}<92 \%\right.$ or respiratory rate $\left.<10 \mathrm{bpm}\right)$ and blood losses also recorded (estimated in graded suction bottle and observation of soaked materials). If during surgery a patient reported discomfort, analgesia was provided with fentanyl $1 \mu \mathrm{g} / \mathrm{kg}$ (repeated once), if discomfort continue protocol allow conversion to general anesthesia.

Time intervals recorded were as follow: time from arrival in the operating room till subarachnoid injection of hyperbaric bupivacine, times from subarachnoid injection to T6 sensory level, to maximum bromage scale, to skin incision, and to uterine incision, time from uterine incision to delivery, time from skin incision to surgical closure and PACU stay time.

The clinical data were recorded on a report from these data were tabulated and analyzed. Software (SPSS, version 20.0, for windows, SPSS inc, Chicago, IL) was used for the univariate, bivariate and stratified analysis of the data. Qualitative variables were analyzed by constructing contingency tables with pearson $\chi^{2}$ test or fisher exact test, when conditions for the former were not met. Analysis of variance ANOVA test ( $t$ test) was applied for the comparison of quantitative variables after establishing their normal distribution by means and standard deviation, differences were considered significant at $\mathrm{P}=0.05$.

\section{Results}

All 120 recruited patients completed the study without any protocol contraventions. Demographic data presented in Table 1. There were significant difference between groups regarding the weight and BMI with parturients ranged in group A (weight $58-83 \mathrm{Kg}$, BMI $22.2-29.9 \mathrm{~kg} / \mathrm{m}^{2}$ ), group B (weight $80-130 \mathrm{~kg}$, BMI $32.4-44.7 \mathrm{~kg} / \mathrm{m}^{2}$ ) and in group C (weight $105-163 \mathrm{~kg}$, BMI $45.7-66.9 \mathrm{~kg} / \mathrm{m}^{2}$ ). No significant differences were observed between groups regarding age and height.

No significant difference in MBP between group A and B during the first 9 readings (45 minutes) but there were significant drops in MBP in groups $C$ (Figure 1). Mean number of hypotensive episodes was significantly higher in 
group $\mathrm{C}$ than group $\mathrm{A}, \mathrm{B}$ with no significant difference in incidence of episodes between group A, B ( $\mathrm{P}<0.001)$ (3.28 vs 3.98 vs 5.98) (Table 2). Total dose of vasopressors and total volume of fluid infused were significantly higher in group $\mathrm{C}$ than group A, B (Table 3 ).

The anesthesia onset time for desired spinal block level T6 was significantly ( $\mathrm{P}$ $<0.001$ ) shorter in group B than group A and in group C than in group A, B ( $3.55 \pm 0.78$ vs $3.08 \pm 0.69$ vs $2.78 \pm 0.48$ minutes) in group $A$ the maximum block level extended above $\mathrm{T} 3$ in 5 patients $(12.5 \%)$, with predominance of $\mathrm{T} 5$ (35\%), in group B, the maximum level extended above T3 in 10 patients (25\%) with predominance of $\mathrm{T} 4(45 \%)$ and in group $\mathrm{C}$ the maximum block level extended above T3 in 21 patients (52.5\%) with predominance of T3 (32.5\%) (Table 3).

Table 1. Demographic data.

\begin{tabular}{cccccc}
\hline & Group A (40) & Group B (40) & Group C (40) & ANOVA test (F) & P-value \\
\hline Age & $29.58 \pm 4.99$ & $29.25 \pm 5.58$ & $31.63 \pm 5.37$ & 2.34 & 0.10 \\
Weight & $71.87 \pm 6.58$ & $102.94 \pm 11.7^{\mathrm{a}}$ & $130.7 \pm 20.44^{\mathrm{ab}}$ & 173.9 & $<0.001^{\star *}$ \\
Height & $63.28 \pm 2.42$ & $62.68 \pm 2.78$ & $63.1 \pm 2.72$ & 0.55 & 0.58 \\
BMI & $28.1 \pm 1.94$ & $40.45 \pm 3.67^{\mathrm{a}}$ & $51.88 \pm 7.52^{\mathrm{ab}}$ & 230.2 & $<0.001^{\star *}$ \\
\hline
\end{tabular}

Table 2. Side effects.

\begin{tabular}{cccccc}
\hline Adverse effects & Group A (40) & Group B (40) & Group C (40) & $\chi^{2}$ & P-value \\
\hline Hypotension episodes & $3.28 \pm 2.31$ & $3.98 \pm 1.54$ & $5.98 \pm 2.38^{\mathrm{ab}}$ & $\mathrm{F}=17.61$ & $<0.001^{\star *}$ \\
Nausea & $8(20.0)$ & $10(25.0)$ & $15(37.5)$ & $\chi^{2}=3.26$ & 0.20 \\
Vomiting & $3(7.5)$ & $3(7.5)$ & $4(10.0)$ & FET $=0.32$ & 1.0 \\
Pruritis & $7(17.5)$ & $11(27.5)$ & $9(22.5)$ & $\chi^{2}=1.15$ & 0.56 \\
\hline
\end{tabular}

a: sig against gp A; b: sig against gp $\mathrm{B}{ }^{*}=$ sig; ${ }^{\star *}=$ highly sig.

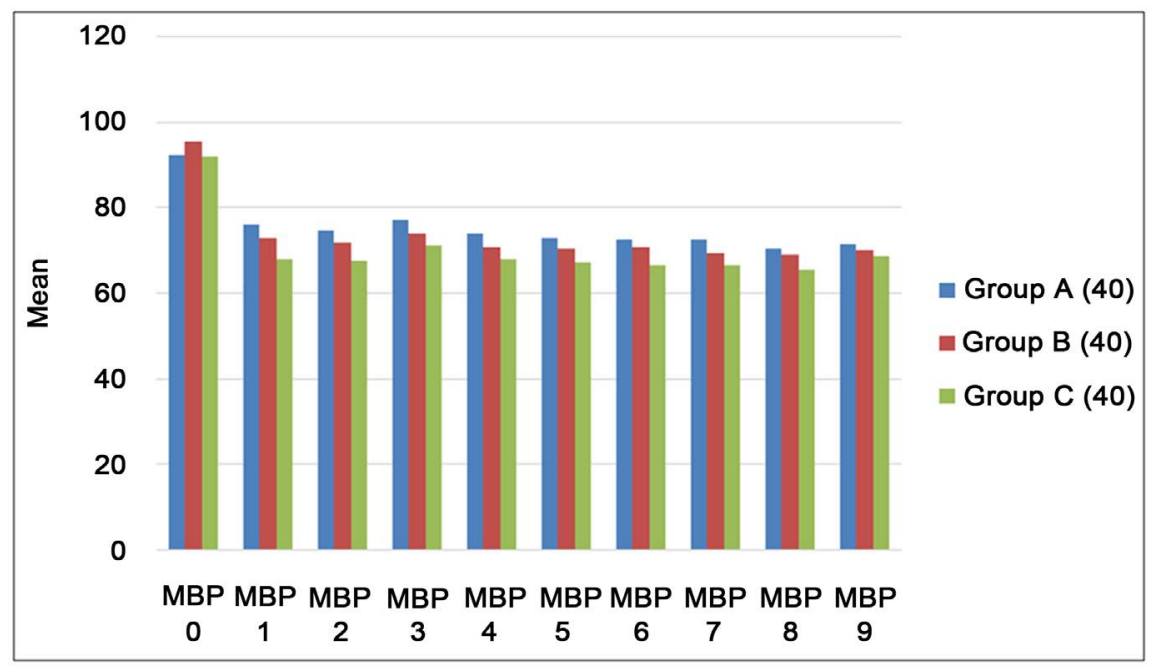

Figure 1. Significant drop in MBP in group C than group A, B during first 9 readings (45 min) with no significant difference between group A, B. 
Table 3. Anaesthesia characteristics and neonatal outcome.

\begin{tabular}{|c|c|c|c|c|c|}
\hline & Group A (40) & Group B (40) & Group C (40) & F Test & $P$-value \\
\hline $\begin{array}{l}\text { Time to } \\
\text { reach T6 }\end{array}$ & $3.55 \pm 0.78$ & $3.08 \pm 0.69 a$ & $2.78 \pm 0.48 \mathrm{ab}$ & 13.84 & $<0.001^{* *}$ \\
\hline \multicolumn{6}{|l|}{$\begin{array}{c}\text { Peak } \\
\text { sensory level }\end{array}$} \\
\hline $\mathrm{T} 2$ & $2(5.0)$ & $4(10.0)$ & $8(20.0)$ & & \\
\hline $\mathrm{T} 3$ & $3(7.5)$ & $6(15.0)$ & $13(32.5)$ & & \\
\hline $\mathrm{T} 4$ & $12(30.0)$ & $18(45.0)$ & $12(30.0)$ & $\mathrm{FET}=29.4$ & $<0.001^{\star *}$ \\
\hline T5 & $14(35.0)$ & $12(30.0)$ & $7(17.5)$ & & \\
\hline T6 & $9(22.5)$ & $0(0.0)$ & $0(0.0)$ & & \\
\hline $\begin{array}{l}\text { Time to max. } \\
\text { Bromage scale }\end{array}$ & $3.45 \pm 0.71$ & $3.05 \pm 0.64 \mathrm{a}$ & $2.53 \pm 0.51 \mathrm{ab}$ & 22.0 & $<0.001^{* *}$ \\
\hline $\begin{array}{c}\text { Duration of } \\
\text { sensory block }\end{array}$ & $129.3 \pm 12.93$ & $132.25 \pm 7.3$ & $141.15 \pm 12.6 \mathrm{ab}$ & 15.22 & $<0.001^{\star *}$ \\
\hline $\begin{array}{l}\text { Duration of } \\
\text { motor block }\end{array}$ & $135.5 \pm 13.9$ & $139.6 \pm 10.7$ & $148.6 \pm 11.6 \mathrm{ab}$ & 15.17 & $<0.001^{\star *}$ \\
\hline $\begin{array}{c}\text { PACU } \\
\text { stay time }\end{array}$ & $138.75 \pm 14.31$ & $142.88 \pm 9.9$ & $152.5 \pm 6.8 \mathrm{ab}$ & 22.5 & $<0.001^{\star *}$ \\
\hline $\begin{array}{l}\text { Total fluid } \\
\text { volume }\end{array}$ & $2193.75 \pm 399.23$ & $2476.25 \pm 494.97 \mathrm{a}$ & $2896.25 \pm 345.74 \mathrm{ab}$ & 28.62 & $<0.001^{\star *}$ \\
\hline $\begin{array}{l}\text { Estimated } \\
\text { blood loss }\end{array}$ & $646.25 \pm 93.64$ & $715.0 \pm 76.12 \mathrm{a}$ & $781.25 \pm 98.51 \mathrm{ab}$ & 22.53 & $<0.001^{\star *}$ \\
\hline Urine output & $136.38 \pm 59.51$ & $130.13 \pm 55.45$ & $139.25 \pm 43.3$ & 0.31 & 0.74 \\
\hline $\begin{array}{c}\text { Dose of } \\
\text { ephedrine }\end{array}$ & $\begin{array}{c}15.15 \pm 7.01 \\
(\mathrm{n}=33)\end{array}$ & $\begin{array}{c}15.69 \pm 5.63 \\
(\mathrm{n}=36)\end{array}$ & $\begin{array}{c}26.5 \pm 11.78 \mathrm{ab} \\
(\mathrm{n}=40)\end{array}$ & 20.34 & $<0.001^{* *}$ \\
\hline $\begin{array}{c}\text { Dose of } \\
\text { phenylephrine }\end{array}$ & $\begin{array}{c}148.33 \pm 98.68 \\
(\mathrm{n}=30)\end{array}$ & $\begin{array}{c}141.67 \pm 56.7 \\
(\mathrm{n}=36)\end{array}$ & $\begin{array}{c}211.25 \pm 93.02 \mathrm{ab} \\
(\mathrm{n}=35)\end{array}$ & 7.81 & $0.001^{\star *}$ \\
\hline PEF baseline & $363.0 \pm 36.0$ & $357.13 \pm 31.86$ & $352.5 \pm 25.57$ & 1.12 & 0.33 \\
\hline PEF-30 min & $343.75 \pm 35.06$ & $335.63 \pm 32.96$ & $320.38 \pm 24.0 \mathrm{ab}$ & 5.85 & $0.004^{\star *}$ \\
\hline Apgar 1 min & $8.03 \pm 0.83$ & $7.90 \pm 0.81$ & $7.45 \pm 1.11 \mathrm{ab}$ & 4.26 & $0.016^{\star}$ \\
\hline Apgar 5 min & $8.9 \pm 1.03$ & $8.95 \pm 0.82$ & $8.45 \pm 1.11 \mathrm{ab}$ & 3.08 & $0.05^{\star}$ \\
\hline $\mathrm{UCPH}$ & $7.274 \pm 0.006$ & $7.272 \pm 0.008$ & $7.265 \pm 0.011 \mathrm{ab}$ & 12.15 & $<0.001^{\star *}$ \\
\hline $\begin{array}{c}\text { No of } \\
\text { attempts }\end{array}$ & $1.03 \pm 0.16$ & $1.13 \pm 0.404$ & $1.35 \pm 0.70 \mathrm{ab}$ & 4.9 & $0.009^{* *}$ \\
\hline $\begin{array}{l}\text { Arrival to } \\
\text { induction }\end{array}$ & $13.28 \pm 1.74$ & $16.95 \pm 4.2 \mathrm{a}$ & $20.33 \pm 5.39 \mathrm{ab}$ & 30.05 & $<0.001^{\star *}$ \\
\hline $\begin{array}{l}\text { Induction } \\
\text { to skin }\end{array}$ & $13.7 \pm 3.13$ & $14.05 \pm 3.0$ & $14.5 \pm 3.07$ & 0.68 & 0.51 \\
\hline Induction to ut & $20.98 \pm 3.05$ & $23.03 \pm 3.17 \mathrm{a}$ & $26.28 \pm 2.94 \mathrm{ab}$ & 30.67 & $<0.001^{\star *}$ \\
\hline Ut to delivery & $48.88 \pm 16.47$ & $53.5 \pm 14.77$ & $63.5 \pm 16.53 \mathrm{ab}$ & 8.79 & $<0.001^{\star *}$ \\
\hline $\begin{array}{c}\text { Skin incision } \\
\text { to closure } \\
\text { (surgery duration) }\end{array}$ & $43.7 \pm 5.13$ & $49.1 \pm 5.28 \mathrm{a}$ & $56.18 \pm 6.43 \mathrm{ab}$ & 49.19 & $<0.001^{\star *}$ \\
\hline
\end{tabular}

a: sig against gp A; b: sig against gp B; * sig; ${ }^{* *}=$ highly sig. 
The time of sensory block to regress below L1 was significantly prolonged in group C than group A, B but no significant difference between group A, B (P < $0.001)(129.3 \pm 12.9$ vs $132.25 \pm 7.3$ vs $141.15 \pm 12.6$ minutes). The time of motor block to reach maximum bromage score was shorter in group $\mathrm{C}$ than group A, B ( $3.45 \pm 0.71$ vs $3.05 \pm 0.64$ vs $2.53 \pm 0.51$ minutes). The time of motor block recovery was significantly shorter in group A, B than group C, with no significant difference between group A, B $(135.5 \pm 13.9$ vs $139.6 \pm 10.7$ vs $148.6 \pm 11.6$ minutes). The length of PACu stay significantly longer in group $\mathrm{C}$ than other two groups $(\mathrm{P}<0.001)(138.75 \pm 14.3$ vs $142.87 \pm 9.9$ vs $152.5 \pm 6.8$ minutes $)$.

The time taken from arrival in the O.R until injection of subarachnoid bupivacine was significantly longer in group $B$ than group $A$ and in group $C$ than group A, B (13.28 \pm 1.74 vs $16.96 \pm 4.2$ vs $20.3 \pm 5.39$ minutes) (Table 3$)$ there were also significant difference between groups in the mean times taken from injection of subarachnoid bupivacine to uterine incision, uterine incision to delivery and skin incision to skin closure, but no difference between groups in the mean time taken from subarachnoid injection to skin incision. There was significant difference in the mean of estimated blood loss between groups (646.25 \pm 93.64 vs $715.0 \pm 76.12$ vs $781.25 \pm 98.5 \mathrm{ml})(\mathrm{p}<0.001)$ (Table 3$)$.

No difference between the groups could be demonstrated with regard to baseline mean PEFR but there was significant decrease in group $C$ than the two other groups in the mean of PEFR 30 minutes after subarachnoid injection (343.75 \pm 35.06 vs $335.63 \pm 32.96$ vs $320.38 \pm 24.0 \mathrm{ml}$ ) (Table 3 ). The mean number of spinal attempts was significantly greater in group $C$ than group $A, B(P=0.004)$ $(1.03 \pm 0.16$ vs $1.13 \pm 0.4$ vs $1.35 \pm 0.7)$ (Table 3$)$.

Nausea and/or vomiting occurred in 11 patients in group A, 13 in group B and 19 patients in group C. Pruritis noted in all groups with no significant difference (Table 2). No patients required intraoperative analgesic supplementation or general anesthesia conversion, in group $\mathrm{C}, 5$ patients required $\mathrm{O}_{2}$ supplementation via nasal cannula, in group $\mathrm{A}, \mathrm{B}$ the respiratory rate of all patients maintained above 10 breaths per minutes and $\mathrm{O}_{2}$ saturation above $92 \%$ in all patients, with no reported cases of respiratory depression.

\section{Discussion}

There is debate about the dose of hyperbaric bupivacine for spinal anesthesia for cesarean section in obese parturients. While it is concessive that the dose of spinal bupivacine is reduced in pregnant compared to non pregnant patients [5], due to factors such as change of permeability of neural tissue to local anesthetics as result of pregnancy hormonal changes or enhanced spread of spinal local anesthetics due to engorgement of epidural venous plexus [6]. It is still controversial whether local anesthetic dose should be further reduced in obese patients. Considering that he higher incidence of hypotensive episodes and significant increase in vasopressor doses required to maintain stable blood pressures in group C than group A, B (no significant difference between group A and group B), we 
can conclude that subarachnoid injection of hyperbaric bupivacine $12.5 \mathrm{mg}$ and fentanyl $20 \mu \mathrm{g}$ exert similar haemodynamic effects in parturients with BMI $<30$ $\mathrm{Kg} / \mathrm{m}^{2}$ to those with BMI between $30-45 \mathrm{~kg} / \mathrm{m}^{2}$, but significant haemodynamic changes observed in parturients with BMI $>45 \mathrm{~kg} / \mathrm{m}^{2}$.

Controverse still present about reducing the dose of local anesthetics in obese patients to avoid excessive block while maintaining satisfactory analgesia. About two thirds of serious anesthesia related complications were due to high neuroaxial block. Most of patients who developed high block from regional anesthesia were obese [7]. Reducing the dose of bupivacine may decrease the incidence of hypotention, nausea, requirements of vasopressors, decrease the time to discharge from PACu and improve overall maternal satisfaction [8]. However, reduced dose of subarachnoid local anesthetics may also associate with intraoperative visceral pain, nausea and late anesthesia failure which sometimes mandate conversion to general anesthesia [9]. A study in non obese parturients showed that, the median $50 \%$ and $95 \%$ effective dose $\left(\mathrm{ED}_{50}\right.$ and $\left.\mathrm{ED}_{95}\right)$. For hyperbaric bupivacine with opioid were $7.6 \mathrm{mg}$ and $11.2 \mathrm{mg}$ respectively [10] meta-analysis suggested that in single shot spinal anesthesia in non obese parturients any reduction of the dose of bupivacine to $<8 \mathrm{mg}$ with opioids, resulted in markedly increased requirement for analgesia (risk ratio $=3.76,95 \% \mathrm{CI}=2.38$ to $5.98, \mathrm{P}<$ 0.001) [11]. Petersen et al. [1] [12], found that increasing the subarachnoid dose of bupivacine from 7.5 - 10 to $10-12.5 \mathrm{mg}$ decrease the incidence of visceral pain from $71 \%$ to $32 \%$ confirming the relation between adequate dose and patient satisfaction.

Sensory testing, using touch modality to detect extent of anesthesia, showed that at 25 minutes after spinal anesthesia induction, significant higher level in group $\mathrm{C}$ than the other two groups with maximum block level extended above $\mathrm{T} 3$ in 21 patients (52.5\%) with T3 predominance (32.5\%), while in group B the maximum level extended above T3 in 10 patients (25\%) with predominance of T4 (45\%) and in group A maximum level extended above T3 in 5 patients (12.5\%), with predominance of T5 (35\%).

It has been postulated that there may be increased cephalade spread of local anesthetics in obese patients, because of decrease CSF volume in patients with high BMI, which could explain exaggerated spread of local anesthetics and decrease dose requirement due to decrease anesthetic dilution [13]. Others [14] have referred the decrease in CSF volume to inferior vena cava compression with redistribution of lower limb venous return which causes engorgement of epidural venous plexus and increase epidural space pressure which compress the dural sac and decrease CSF volume. Hogan et al. [13] attributed the mechanism of decrease CSF volume by increased abdominal pressure which causes inward movement of soft tissues through intervertebral foramen displacing CSF from lumbar region. Magnetic resonance imagings have proven the decreased lumbar volume of CSF in obese patients and inverse correlation between cephalade extent of block and lumbar CSF volume [15]. Barclay et al. [16] showed that increasing intraabdo- 
minal pressure with bainder leading to increase the spread of radio-opaque material during myelography with abdominal compression. Greene suggested that [14] obesity per se not increase local anesthetic spread, rather than large buttocks of obese patients which place the vertebral column in trendelenberg position when obese patients positional supine which favour cephalade spread of lo$\mathrm{cal}$ anesthetics. Others thought, the level of puncture in spinal anesthesia in obese is usually higher than intended because pads of fat make the assessment of spinal level by palpation rather inaccurate [17].

Studies that have investigated the relationship between subarachnoid local anesthetic and weight have shown conflicting results. Significant correlation was found by Taivainen et al. [18] in patients receiving isobaric bupivacine $0.5 \%, 15$ $\mathrm{mg}$ for lower limb orthopedic surgery. Moore [19], has shown in 4 groups of 435 patients, when hyperbaric bupivacine or tetracine were used $(7.5$ or $12 \mathrm{mg})$, that higher spread of pin. Prick analgesia with higher BMI. Carpenter et al. [15] showed that there was inverse correlation between cephalade sensory block and CSF volume when a fixed dose of local anesthetic (lidocaine $50 \mathrm{mg}$ ) was used two others have found significant correlation between cephaladi spread of local anesthetic and increasing weight [20] [21], in both studies BMI correlate more significantly with cephalic dispersion of sensory block than did weight alone. Pitkanen gave 70 patients $15 \mathrm{mg}$ isobaric bupivacine and found each increase in BMI with 1 $\mathrm{Kg} / \mathrm{m}^{2}$, increasing analgesic level by one dermatome. McCulloch and Little wood found similar highly significant correlation $(\mathrm{P}<0.001)$ between BMI and cephalic spread of spinal analgesia. Harten et al. [22] randomly assigned patients with heights $140-180 \mathrm{~cm}$ and weights $50-110 \mathrm{~kg}$ to receive either adjusted dose using Harten chart taking into considerations height and weight or fixed dose of hyperbaric bupivacine $12 \mathrm{mg}$ and diamorphine $0.4 \mathrm{mg}$ they concluded that height and weight adjusted dose results in fewer blocks above T1 level and less hypotention but some patients in dose adjusted group required analgesic supplementation, suggesting that dose adjustment may increase analgesic requirements.

Despite investigations showed a tendency towards higher cephalade spread of local anesthetics in obese patients in comparison with patients with normal BMI, Norris [23] showed no correlation between cephalade spread of sensory block and patient BMI; however a fixed dose of hyperbaric bupivacine was used and morbidly obese patients were not included in the study. Saravanan et al. [24] used sequential allocation design and CSE (Combined spinal epidural) technique in parturients weighting $50-120 \mathrm{Kg}$. To find $\mathrm{ED}_{50}(9.95 \mathrm{mg})$ and $\mathrm{ED} 95$ (13.55 $\mathrm{mg}$ ) of intrathecal bupivacine required for cesarean section. Carvalho and Collenges [4] studied the local anesthetic dose required to produce spinal anesthesia in obese versus non obese parturients. Various doses of local anesthetics were given as part of CSE technique they suggested that the dose required to produce successful anesthesia was not different in morbidly obese than non obese parturients. Lee et al. [5] found similarity between obese and non obese parturients in the $\mathrm{ED}_{95}$ for subarachnoid hyperbaric bupivacine with opioids, $12.9 \mathrm{mg}$ (95\% CT 11.5 - $34.8 \mathrm{mg}$ ), using allocation design. Finally retrospective analysis suggested 
that there was no risk of cephalade spread of bupivacine in obese compared with non obese unless BMI is greater than $50 \mathrm{Kg} / \mathrm{m}^{2}$ [25]. In our study the mean (SD) BMI was $51.8 \mathrm{~kg} / \mathrm{m}^{2}$, and although we have only 13 parturient out of 40 had BMI $>50 \mathrm{~kg} / \mathrm{m}^{2}$, there was significant difference in haemodynamics and cephalade spread in group $\mathrm{C}$ than two other groups.

Significant reduction in peak expiratory flow rate in group $\mathrm{C}$ patients than other two groups, 30 minutes after intraothecal injection of hyperbaric bupivacine. This result in agree with the report of Freund et al. [26] who observed, during spinal and epidural anesthesia there were greater spread of sensory and motor block into thoracic area which cause proportionally greater decrease in expiratory reserve volume.

The mean time for regression of motor block, sensory block to below L1 and PACU stay, were longer in group $C$ than other groups also all O.R. related durations were longer in group C. The increased mean duration of surgery in group $\mathrm{C}$ than other groups (43 vs 49 vs 56 minutes). Emphasize the need for careful assessment of the dose of subarachnoid local anesthetic to avoid late spinal anesthesia failure and risk of general anesthesia conversion. Despite regional anesthesia may be more difficult in obese parturients (regarding number of trials), we found no difference in incidence of failure. In our study there were inverse relation between BMI and umbilical cord PH and apgar score, inability to achieve adequate pelvic tilt in patients who are morbidly obese to relieve aorto-caval compression, may be the reason, however, the longer incision to delivery time may be another reason.

In this study, we tried to control many factors known to affect subarachnoid spread of local anesthetics. The L3-4 puncture level was just marked by ultrasound as opposed to inaccurate palpation method. This is of importance in morbidly obese patients, where palpation method is highly inaccurate by as much as 1 - 4 segments [27]. The duration of injection of local anesthesetic solution and time allowed between subarachnoid injection and patient positioning supine were strictly controlled. It was not possible to perform the study in double blind manner as the degree of obesity of parturients cannot be hidden from Judger, but we tried to achieve greater objectivity by allowing a trained individual who was unaware about the nature of the study, to perform the assessment of the level of block in all cases.

\section{Conclusion}

Regarding significant decrease in mean peak expiratory flow rate and increase in vasopressors requirements to maintain stable haemodynamics in parturients with BMI $>45 \mathrm{Kg} / \mathrm{m}^{2}$, while no significant difference between other two groups (parturients with BMI $<30 \mathrm{~kg} / \mathrm{m}^{2}$ and parturients with BMI $30-45 \mathrm{Kg} / \mathrm{m}^{2}$ ). We conclude that intrathecal dose of bupivacine $12.5 \mathrm{mg}$ and fentanyl $20 \mu \mathrm{g}$ resulted in clinically equivalent effect in 2 groups of parturients with differing weight, BMI $<45 \mathrm{~kg} / \mathrm{m}^{2}$ but significant changes in parturients with BMI $>45 \mathrm{~kg} / \mathrm{m}^{2}$. So caution is necessary and dose adjustment is required for this group of patients. This 
is of special importance as malpractice claims against anesthesiologists shown that the most common cause of maternal death/brain damage in regional anesthesia claims was high neuroaxial block and most of patients were obese, this is of special importance in low resources environment where CSE anesthesia not routinely available and subsequent conversion to general anesthesia may associate with catastrophic complications.

\section{Conflicts of Interest}

The author declares no conflicts of interest regarding the publication of this paper.

\section{References}

[1] Langesaeter, E. and Dyer, R.A. (2011) Maternal Haemodynamic Changes during Spinal Anesthesia for Cesarean Section. Current Opinion in Anesthesiology, 24, 242-248. https://doi.org/10.1097/ACO.0b013e32834588c5

[2] Bamgbade, O.A., Khalaf, W.M., Ajai, O., Sharma, R., Chidambaram, V. and Mdhavan, G. (2009) Obstetric Anesthesia Outcome in Obese and Non Obese Parturients Undergoing Cesarean Delivery: An Observational Study. The International Journal of Obstetric Anesthesia, 18, 221-225. https://doi.org/10.1016/j.ijoa.2008.07.013

[3] Dresner, M., Brennan, A. and Freeman, J. (2003) Six Year Audit of High Regional Blocks in Obstetric Anesthesia. The International Journal of Obstetric Anesthesia, 12,510 .

[4] Carvalho, B., Collins, J., Drover, D.R., Atkinson, R.L. and Riley, E.T. (2011) ED50 and ED95 of Intrathecal Bupivacine in Morbidly Obese Patients Undergoing Cesarean Delivery. Anesthesiology, 114, 529-535. https://doi.org/10.1097/ALN.0b013e318209a92d

[5] Lee, Y., Balki, M., Parkes, R. and Carvalho, J.C. (2009) Dose Requirement of Intrathecal Bupivacaine for Cesarean Delivery Is Similar in Obese and Normal Weight Women. Revista Brasileira de Anestesiologia, 59, 674-683. https://doi.org/10.1016/S0034-7094(09)70092-3

[6] Saravanakumar, K., Rao, S.G. and Cooper, G.M. (2006) Obesity and Obstetrics Anesthesia. Anaesthesia, 61, 36-48. https://doi.org/10.1111/j.1365-2044.2005.04433.x

[7] D’Angelo, R., Smiley, R.M., Riley, E.T., et al. (2014) Serious Complications Related Obstetric Anesthesia: The Serious Complications Respiratory Project of the Society for Obstetric Anesthesiology and Perinatology. Anesthesiology, 120, 1505-1512. https://doi.org/10.1097/ALN.0000000000000253

[8] Vercauteren, M.P., Coppejans, H.C., Hoffmann, V.L., Saldien, V. and Adriaensen, H.A. (1998) Small Dose Hyperbaric versus Plain Bupivacine during Spinal Anesthesia for Cesarean Section. Anesthesia \& Analgesia, 86, 989-993.

https://doi.org/10.1213/00000539-199805000-00014

[9] Ben-David, B., Miller, G., Gavriel, R. and Gurevitch, A. (2000) Low Dose Bupivacine-Fentanyl Spinal Anesthesia for Cesarean Delivery. Regional Anesthesia and Pain Medicine, 25, 235-239. https://doi.org/10.1097/00115550-200005000-00005

[10] Ginsora, Y., Mirikatemi, L.E., Drover, D.R., Cohen, S.E. and Riley, E.T. (2004) ED $_{50}$ and $\mathrm{ED}_{95}$ of Intrathecal Hyperbaric Bupivacine Coadministrated with Opioids for Cesarean Delivery. Anesthesiology, 100, 676-682.

https://doi.org/10.1097/00000542-200403000-00031 
[11] Arzola, C. and Wieczorek, P.M. (2011) Efficacy of Low Dose Bupivacine in Spinal Anesthesia for Cesarean Delivery: Systematic Review and Meta-Analysis. British Journal of Anaesthesia, 107, 308-318. https://doi.org/10.1093/bja/aer200

[12] Pedersen, H., Santos, A.C., Steinberg, E.S., Schapiro, H.M., Harmon, T.W. and Finster, M. (1989) Incidence of Visceral Pain during Cesarean Section: The Effect of Varying Doses of Spinal Bupivacine. Anesthesia \& Analgesia, 69, 46-49. https://doi.org/10.1213/00000539-198907000-00009

[13] Hogan, Q.H., Prost, R., Kulier, A., et al. (1996) Magnetic Resonance Imaging of Cerebrospinal Fluid Volume and the Influence of Body Habitus and Abdominal Pressure. Anesthesiology, 84, 1341-1349.

https://doi.org/10.1097/00000542-199606000-00010

[14] Greene, N.M. (1985) Distribution of Local Anesthetic Solutions within the Subarachnoid Space. Anesthesia \& Analgesia, 64, 715-730.

https://doi.org/10.1213/00000539-198507000-00012

[15] Carpenter, R.L., Hogan, Q.H., Liu, S.S., Crane, B. and Moore, J. (1998) Lumbosacral Cerebrospinal Fluid Volume Is the Primary Determinant of Sensory Block Extent and Duration during Spinal Anesthesia. Anesthesiology, 89, 24-29. https://doi.org/10.1097/00000542-199807000-00007

[16] Barclay, D.L., Renegar, O.J. and Nelson, E.W. (1968) The Influence of IVC Compression on the Level of Spinal Anesthesia. American Journal of Obstetrics \& Gynecology, 101, 792. https://doi.org/10.1016/0002-9378(68)90035-5

[17] Hocking, G. and Wildsmith, J.A.W. (2004) Intrathecal Drug Spread. British Journal of Anaesthesia, 93, 568-578. https://doi.org/10.1093/bja/aeh204

[18] Taivainen, T., Tuominen, M. and Rosenberg, P.H. (1990) Influence of Obesity on the Spread of Spinal Analgesia after Injection of Plain 0.5\% Bupivacine at the L3-4 or L4-5 Interspace. British Journal of Anaesthesia, 64, 542-546. https://doi.org/10.1093/bja/64.5.542

[19] Moore, D.C. (1982) Factors Influencing Spinal Anesthesia. Regional Anesthesia, 7, 20-25.

[20] McCulloch, W.J.D. and Littlewood, D.G. (1986) Influence of Obesity on Spinal Analgesia with Isobaric 0.5\% Bupivacine. British Journal of Anaesthesia, 58, 610-614. https://doi.org/10.1093/bja/58.6.610

[21] Pitkanen, M.T. (1987) Bodymass and Spread of Spinal Anesthesia with Pubivacine. Anesthesia \& Analgesia, 66, 127-131. https://doi.org/10.1213/00000539-198666020-00005

[22] Harten, J.M., Boyne, I., Hannah, P., Varveris, D. and Brown, A. (2005) Effects of a Height and Weight Adjusted Dose of Local Anesthetic for Spinal Anesthesia for Elective Cesarean Section. Anesthesia, 60, 348-353. https://doi.org/10.1111/j.1365-2044.2005.04113.x

[23] Norric, M.C. (1990) Patient Variables and the Subarachnoid Spread of Hyperbaric Bupivacine in the Term Parturients. Anesthesiology, 72, 478-482. https://doi.org/10.1097/00000542-199003000-00015

[24] Saravanan, S., Robinson, A., Saxena, S., Wilson, R. and Lyons, G. (2003) The ED95 of Hyperbaric Bupivacine in Spinal Anesthesia for Cesarean Section (Abstract). International Journal of Obstetric Anesthesia, 12, 517.

[25] Einhorn, L., Akushevich, I. and Habib, A.S. (2014) Intrathecal Bupivacine Dose for Cesarean Delivery Is Not Reduced in Obese Compared to Non-Obese Parturients. ASA Annual Meeting, San Francisco, 16-19 August 2014, A4206. 
[26] Freund, F.C., Bonica, J.J., Ward, R.J., Akamatsu, T.J. and Kennedy Jr., W.F. (1967) Ventilatory Reserve and Level of Motor Block during High Spinal and Epidural Anesthesia. Anesthesiology, 28, 834-837. https://doi.org/10.1097/00000542-196709000-00011

[27] Whitty, R., Moore, M. and Macarthur, A. (2008) Identification of the Lumbar Interspinous Spaces: Palpation versus Ultrasound. Anesthesia \& Analgesia, 106, 538-540. https://doi.org/10.1213/ane.0b013e31816069d9 